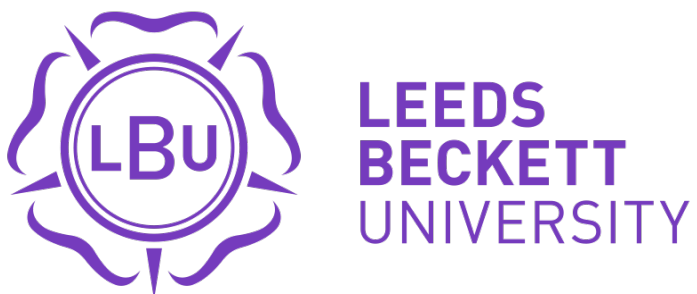

Citation:

Wood, EH (2009) An impact evaluation framework: Local government community festivals. Event Management, 12 (3-4). 171 - $185 . \quad$ ISSN 1525-9951 DOI: https://doi.org/10.3727/152599509789659768

Link to Leeds Beckett Repository record:

https://eprints.leedsbeckett.ac.uk/id/eprint/1014/

Document Version:

Article (Published Version)

The aim of the Leeds Beckett Repository is to provide open access to our research, as required by funder policies and permitted by publishers and copyright law.

The Leeds Beckett repository holds a wide range of publications, each of which has been checked for copyright and the relevant embargo period has been applied by the Research Services team.

We operate on a standard take-down policy. If you are the author or publisher of an output and you would like it removed from the repository, please contact us and we will investigate on a case-by-case basis.

Each thesis in the repository has been cleared where necessary by the author for third party copyright. If you would like a thesis to be removed from the repository or believe there is an issue with copyright, please contact us on openaccess@leedsbeckett.ac.uk and we will investigate on a case-by-case basis. 


\title{
AN IMPACT EVALUATION FRAMEWORK: LOCAL GOVERNMENT COMMUNITY FESTIVALS
}

\author{
EMMA H. WOOD
}

UK Centre of Event Management, Leeds Metropolitan University, Leeds, UK

\begin{abstract}
This article brings together the author's previous research and consultancy along with a review of literature from several disciplines to develop a framework that summarizes the concepts, methods, and processes required to successfully evaluate the impacts of local government community festivals. Events and festivals are a relatively underresearched area but have experienced a growing amount of public sector expenditure. The framework developed and presented here is in response to the need to encourage greater evaluation of this activity and in doing so recognize the complexity of the process. The impacts of many such festivals are diverse (economic, social, environmental), far reaching (local, national, international), and long term. The evaluation of these impacts, therefore, requires an understanding of the concepts involved and the development of a range of tools and methods. The proposed framework is informed by the empirical research, theory, and practice in the areas of information systems, marketing communications, event studies, and public sector evaluation. Bringing together these distinct but related fields of study has enabled the development of a comprehensive and novel approach to event impact evaluation.
\end{abstract}

Key words: Evaluation; Festivals; Public sector; Event impacts; Event management

Introduction and Context

The growing interest in evaluating the economic and social impacts of local authority provision of festivals and events has been partly led by the increasing need for openness and transparency within local government spending and the requirement to demonstrate a return on the use of public funds. This is illustrated, for example, by the need to conform to government directives related to performance measurement such as the "best value" and "strategic added value" frameworks (Liddle, 1999). The other main driver has been recognition in the academic literature that there is a need for greater research and understanding of the conceptual and practical issues relating to holistic event impact evaluation (Sherwood, Jago, \& Deery, 2000). These calls for research emanate largely from Australia and the US, where there has traditionally been a greater amount of event management research driven mainly by the recent hosting of large-scale events such as the Olympics. Several studies have shown that not only are the wider impacts of events and festivals still not understood, but that also the practice of impact evaluation lacks consistency and comprehensiveness for a wide range of events (Carlsen, Getz, \& Soutar, 2001; Sherwood et al., 2000). This is further evidenced with- 
in Marcouiller's (1995) research, which concludes that promoting and hosting festivals and special events can be a good community development strategy but may have limited effectiveness as an economic development strategy.

The terms "events" and "festivals" encompass a wide variety of occurrences ranging from large-scale international sporting events to village fetes. The focus of this article, however, is those festivals that are community based and have some level of local government involvement. Whereas events tend to be defined very broadly as any type of planned happening or occurrence (Getz, 2002), festivals are more often understood as events that incorporate some aspect of celebration (Getz, 2005; Goldblatt \& Nelson, 2001; Janiskee, 1980). A festival is described as a public themed celebration that should be by and for the public (Getz, 2005). In this definition the term festival describes non-private sector events and starts to suggest the importance of community within festival provision. Indeed, Falassi (1987, p. 2) states that the social function and the symbolic meaning of the festival are closely related to a series of overt values that the community recognizes as essential to its ideology and worldview, to its social identity, its historical continuity, and to its physical survival, which is ultimately what the festival celebrates. A festival, therefore, must involve the idea of community in some form and encompass a celebration of some aspect of this community.

As the focus of the evaluation framework is on local government community-based festivals it is important to discuss the term community as it relates to events. Although, within sociology, community is defined in terms of interactions rather than locality, others in the fields of tourism, social geography, health, and arts have tended to move to broader definitions. Communities can therefore be defined by geography, shared interest, or characteristic or collective action (Green \& South, 2006; Hall \& Richards, 2003). Blaug, Horner, Kenyon, and Lekhi (2006) identify that communities are often defined by geographical location, communities of interest, shared values, or levels of attachment, but recognize that rightly or wrongly policy makers focus on the importance of place as this links more readily to local service provision, areas of deprivation, etc. Although this is the case in public sector provision of community festivals (due to the geographical boundaries inherent within local government), within these boundaries the other integrating factors of shared interests, history, or characteristics are also recognized as being important in community definition, depending upon the particular festival being considered.

The existence of communities, and therefore community festivals to some extent, are seen as a means to an end within local and national government policy. For example, community cohesion is seen as preventing civic unrest and exclusion, and community pride is believed to reduce crime levels. It is therefore important that festival evaluations interpret and define community within the context of the event. As in other areas of community projects and initiatives, active community participation in the event suggests the need for participation in the evaluation (Beattie, 1995; Springett, 2001).

The levels of participation in the festival by both the community and the local authority can be used to create the beginnings of a typology of local government community events (Fig. 1). This ranges from festivals located within a community and approved by local government (i.e., very little involvement by either) to those that are created, organized, and participated in by both. For the purpose of this study, a local government community festival requires at least the support of local government and the attendance of local community members. This leaves a range of levels of involvement but ensures the inclusion of all those festivals where evaluation (and impacts) will be of importance to both parties.

The proliferation of community festivals and the growth of local government intervention in these is seen by Long and Robinson (2004) as stemming partly from a lack of traditional events/history to bring everyone together and an increase in population diversity and mobility. They argue that community festivals serve to help create a shared identity in areas where population changes and increased mobility can lead to a lack of stability and continuity. However, these festivals that are ostensibly by and for the community are increasingly exposed to the tourist glare and must therefore function with changing audiences, social objectives, and often new global pressures. Festivals are therefore "occasions by which a local community can legitimise, establish, display or embellish its collective identity and provide the tourist with the opportunity to temporarily confront and engage with aspects of 'otherness' expressed in the context of celebration" (Long \& Robinson, 2004, p. 8).

Over the last few decades there appears to have been a period of unchecked growth in the use of festivals by 


\begin{tabular}{|c|c|c|c|c|c|}
\hline $\begin{array}{l}\text { Level of } \\
\text { involvement }\end{array}$ & $\begin{array}{l}\text { Community } \\
\text { located }\end{array}$ & $\begin{array}{l}\text { Community } \\
\text { attendance }\end{array}$ & $\begin{array}{l}\text { Community } \\
\text { participation }\end{array}$ & $\begin{array}{l}\text { Community } \\
\text { organised }\end{array}$ & $\begin{array}{l}\text { Community } \\
\text { created }\end{array}$ \\
\hline $\begin{array}{l}\text { Local } \\
\text { government } \\
\text { permitted }\end{array}$ & $\begin{array}{l}\text { Little or no } \\
\text { involvement } \\
\text { either party }\end{array}$ & & & & $\begin{array}{c}\text { High } \\
\text { community } \\
\text { involvement }\end{array}$ \\
\hline $\begin{array}{l}\text { Local } \\
\text { government } \\
\text { supported/ }\end{array}$ & & & & & \\
\hline endorsed & & \multicolumn{3}{|c|}{ Increasing level of partnership and involvement } & \\
\hline $\begin{array}{l}\text { Local } \\
\text { government } \\
\text { resourced } \\
\text { /funded }\end{array}$ & & & & & \\
\hline $\begin{array}{l}\text { Local } \\
\text { government } \\
\text { created }\end{array}$ & $\begin{array}{c}\text { High local } \\
\text { government } \\
\text { involvement }\end{array}$ & & & & $\begin{array}{c}\text { High } \\
\text { involvement } \\
\text { both parties }\end{array}$ \\
\hline
\end{tabular}

Figure 1. Local government and community festival involvement.

local authorities (the bandwagon effect), suggesting that these festivals are often staged with insufficient planning, strategy, and forethought (Pugh \& Wood, 2004; Thomas \& Wood, 2003). This highlights the need to develop tools and techniques that are theoretically sound as well as practically relevant in order to encourage planning and strategy within this area and increase the effectiveness of expenditure on festivals and events related to carefully developed objectives.

In pursuing these research interests it is now necessary to place less emphasis on, the well-established, economic impact of events. This is in line with the growing recognition by the arts and events sectors that more substantial benefits can be demonstrated through the inclusion of social impacts within service evaluation frameworks. Indeed, other authors have repeatedly called for less emphasis on economic impacts and management of the event and more focus on events and community, people, and the environment (Carlsen et al., 2001; Getz, 2000; Harris, Jago, Allen, \& Huyskens, 2001). This should not lead to the exclusion of economic impact but the development of a more rounded and multidimensional approach.
There is a growing amount of literature, within tourism economics, arts and culture, and event studies, that considers impact analyses and covers economic, social, cultural, and environmental impacts (see, e.g., Matheson, 2004; Stone, 2001; Vaughan, Farr, \& Slee, 2000). However, most of this literature (with the exception of economic impact research) relates to theoretical constructs within these sectors, with very little empirical testing.

The public sector departments responsible for event provision tend to have limited resources in terms of funding, time, and some areas of staff expertise. This is to be expected in small private sector firms but is, perhaps, more surprising in local government where the events department is part of a much larger organization (Thomas \& Wood, 2003; Wood, 2002a, 2006a). However, it appears that, despite the resources of the larger organization, many departments operate in relative isolation with their own budgets and limited use of shared resources such as organization-wide information systems (Bolton, 2003; Boyett, 1996; McAdam \& Reid, 2000). Indeed, the unsettled environment of much of the last 20 years in the public sector, continu- 
ous reallocation of public expenditure, and devolution of resource ownership to unit level accompanied by the opening up of much provision to market forces has led to greater similarities with the private sector and an increase in entrepreneurial type activities within some public sector areas (Boyett, 1996).

Public Sector Event Provision: Strategy, Analysis, and Evaluation

The debate as to whether the public sector should be more "business-like" and be answerable to its customers continues within much of the public sector marketing literature (Cousins, 1990; McAdam \& Reid, 2000; Smith \& Saker, 1992; Walsh, 1994) and in some part supports the premise, above, that local government departments have much in common with small private sector firms. However, despite the similarities, vital differences exist in that the public sector is accountable to the citizen and the electorate rather than to the customer (although these may well be the same person) (Worrall, Collinge, \& Bill, 1998). Although their resource constraints may be similar, their goals, levels of accountability, and raison-d'être are fundamentally different. Any evaluation of performance has political connotations but these can be both greater and more sensitive within the public sector (Hambleton \& Thomas, 1995). Any form of policy analysis, including event impact analysis, therefore has to take account of these factors (Yanov, 2000). These aspects are incorporated within the framework, presented towards the end of this article, through recognition of the different levels of "stakeholders" and the variety of objectives that may exist that are not always explicitly stated or shared by these stakeholders.

A recent national survey of local government event provision shows that public sector events provision is located within a variety of departments ranging from marketing and regeneration to leisure and tourism. To some extent this reflects the main objectives of the events provided and the level of strategic planning that goes into them (Thomas \& Wood, 2003). However, regardless of their structural location, the fact that they are initiated, produced, and/or managed by local government creates a number of challenges, opportunities, and constraints.

Most event departments responding to the 2003 survey did not set clear objectives for their festival programs and, partly as a consequence, did not undertake any meaningful evaluation (Thomas \& Wood, 2003). A more focused study within London Borough Councils confirmed this nonstrategic use of events (Pugh \& Wood, 2004). Through undertaking projects in festival evaluation (Blackburn Fiesta, Arts in the Park, Blackburn Mela, Preston Mela, Saltaire Festival) it became clear that there were a number of reasons for the lack of strategic planning. One was limited time and money and the other was a vicious circle relating to evaluation and objectives (an event without objectives cannot be easily evaluated and objectives for future events need to be based on past event evaluations). It appears, therefore, that the public sector is funding and organizing a large number and type of events (Jago, 2004; Sherwood et al., 2005) but with little information regarding what they can and do achieve. Their accountability to the citizen is therefore limited in this respect and is an area that needs to be addressed.

This lack of evaluation may, in part, be due to the perceived cost of evaluation when compared to the budget for the event; however, it is proposed here that meaningful evaluation on a minimal budget can be achieved and that the benefits of such evaluation, if used appropriately, far outweigh the costs.

For example, public sector organizations accumulate large volumes of information covering many aspects of the society they serve. This information tends to be comprehensive, longitudinal (or at least collected over decades), and generally accurate (Hadi \& McBride, 2000). However, although knowledge management is well accepted within the public sector (McAdam \& Reid, 2000), other studies have found that much of the information is collected within disparate systems, is operationally (rather than strategically) focused, and that sharing is limited due to departmental barriers and subcultures (Hackney \& McBride, 2004). The existing resource of information and systems to manage it can therefore only be tapped into through extending a culture of sharing and transparency and then it can be augmented through thorough and ongoing event impact evaluation.

The need for transparency, to provide evidence of value, and to ensure the achievement of longer term objectives in the public sector means that there is an even greater need for reliable, applicable, and, to some extent, standardized measurement tools and techniques. These need to be practical and require minimal resources yet generate sufficient objective, quantifiable, and comparable data (Wood, Robinson, 
\& Thomas, 2006). This article presents the development of a specific impact evaluation framework from a theoretical basis making use of workable tools, unique scales, and an overall methodology that is suitable for the specific needs of local government and community festival planners. Although this framework provides a holistic view of community festival impacts, there is still much work to do on developing a wider range of methods suitable for assessing many of the impacts.

Impacts of Community Festivals:

Recognizing the Potential

Impacts are, in effect, all outcomes (planned or otherwise). The objectives set for a festival will therefore be closely related to these and should be planned for, measured, and evaluated. As it is unlikely that all the potential impacts of a festival will be measured, clear objectives are needed to help focus the evaluation resources. These can be in terms of both benefits and costs, for example, to increase community participation in cultural activities; to limit the parking problems associated with the event. Too often, though, the impacts are thought of as side effects that need to be recognized but are beyond the control of the event planner. This is particularly true of those impacts that do not have a direct economic cost or benefit.

Over the last 10 years there has been a marked increase in research aiming to identify the potential impacts of all types of events and more recently the emphasis has begun to move away from the economic impact models adopted from the tourism literature towards the identification and investigation of social impacts (e.g., Fredline, Jago, \& Deery, 2003; Small, Edwards, \& Sheridan, 2005). These impacts are often more marked for community festivals and are more closely related to the original objectives of the event. Although a return on investment is more acceptably measured in financial terms, any real community gain is often through the more intangible impacts relating to community, society, and culture. This has been identified through trialing a range of evaluation techniques covering potential social benefits. In the majority of cases these were found to be substantial in comparison to the direct economic impacts.

Festivals organized and/or funded by local government and participated in and attended by the local community can be seen as communication vehicles, and viewing them as such helps to clarify their objectives and, therefore, their potential impacts. These range from promoting a general "feel good" factor in the community, through celebration and entertainment, to promoting pride in the region, acceptance of cultures, community cohesion, a feeling of belonging, and more active citizenship (Derrett, 2002; Quinn, 2005; Richards \& Wilson, 2004). Local government festivals, therefore, can promote the area, the local culture and subcultures, participation in arts, sport, and education, and encourage a positive attitude to the event provider, the council.

Although there has been a growth in social/cultural impact analysis there is very little standardization and the main areas of study tend to involve large-scale sports events. Sherwood et al. (2005) advocate a holistic triple bottom line approach, which is standardized as in other areas of the tourism industry and wider business contexts. However, community festivals with public sector involvement require evaluation and assessment methods specific to their resources and objectives. Indeed, every impact evaluation should be tailored to the objectives of those events. The issue for this type of event is more likely to lie in recognizing the potential of such festivals and then in using this potential to produce events that meet clearly articulated and measurable objectives. This creates a positive cycle based on the measurement of objectives that then informs the creation of future events. Currently, festivals are often hosted with ill-thought-out objectives, which are then not assessed, leaving evaluation to the basics of attendance counts, questionable economic impact measures, and assessment of the functional aspects of the event (Pugh \& Wood, 2004; Thomas \& Wood, 2003).

Current practice within local government festival provision shows a lack of holistic evaluation. In Australia a scrutiny of 84 government agency event assessments found that the rhetoric of "triple bottom line" is being ignored and the focus is essentially economic with no attempt to integrate assessments into a more holistic format (Sherwood et al., 2005). In the UK, a survey of local authorities showed even less evaluation taking place. Indeed, many departments did not undertake any type of evaluation and those that did focused on attendance figures, participant feedback, and attendee satisfaction (Thomas \& Wood, 2003).

\section{Methodological Development}

A thorough understanding of the impacts of community events and the development of ways to evalu- 
ate and measure these could not be achieved without embracing a range of methods and techniques. These are needed to take greater account of the views and opinions of the people involved.

Quantitative methods have been used successfully through the development of survey instruments to measure the economic and social impacts of events but that fit the needs of local authority departments in terms of simplicity, robustness, and ease of analysis (Wood, 2004a, 2006b). Previous client-led research initially focused on economic impact on the local community but through discussion this was extended to include social impacts. These client-driven projects favored quantitative closed questions and large samples, as these were seen as providing "hard data" by the clients. However, whenever possible it was recommended that these were combined with further qualitative data (e.g., from resident panels) in order to give a deeper understanding of the complexities of these impacts rather than merely measuring them. The research conducted for Blackburn with Darwen Marketing and Regeneration Department involved a conceptual and practical framework developed and tested at two of their community events. Although this framework was subsequently refined through further development of the methods it was seen as already improving the levels of decision making within local authority events departments. The largely quantitative methods used at Blackburn with Darwen were improved upon and extended for Preston Mela and included a discussion forum with key stakeholders to refine and further understand the quantitative findings (Wood \& Thomas, 2003).

In order to assess the social impacts of local public sector community festivals a method was needed to measure and compare these factors before and after each festival. This type of instrument is fraught with difficulties as it requires a form of social experiment and, therefore, the exclusion of other contributing variables. Despite these difficulties previous studies have successfully used multi-item scales to measure a range of attitudes, beliefs, and feelings and it was felt that these could be adapted (from the marketing research and marketing communication fields) to fit the needs of event impact measurement. With this end in mind, a multi-item quantitative scale was developed to measure the impact of community festivals on the factor defined as “civic pride.” This initially required selecting items that would reliably define and measure this concept and then decisions on how best to administer such a scale in order to determine changes in the construct (civic pride) related to the hosting of an event. The scale was then developed, tested, and refined through application at three festivals (Blackburn Arts in the Park, Blackburn Fiesta, and Saltaire Festival). In all cases the refined scales had construct and content validity and reliability (tested through comparison with qualitative statements and the use of Cronbach's alpha coefficient). The application of the measure before and after the events were held, therefore, gave a reliable measure of changes in civic pride over the period. However, it is with greater difficulty that any changes can be directly attributed to the hosting of the event. The changes attributable to the event need to be followed up through other research methods, which attempt to discover the reasons for any change. Despite these difficulties, it did appear that events held in areas of generally low civic pride have the propensity to impact positively upon this and a program of sustained events can help ensure that this change is maintained in the longer term (Wood, 2002b). However, in areas where civic pride is already high such festivals are unlikely to make a significant difference and may, indeed, result in lower levels for some members of the community who perceive the event as "not for them" (Wood \& Thomas, 2006). This type of scale forms part of the recommended framework for event impact evaluation but it is recognized that further research is required to develop and test similar scales for the other social impacts identified.

Although unique and with high statistical validity (i.e., they accurately measure the concept in question), a bank of quantitative scales is not sufficient to measure and understand the complexities of the social impacts of events. Complementary methods are needed such as discussion forums, resident panels, and Web-based communities. Discussion forums are used to better understand and explain the findings from the quantitative surveys by presenting these findings to a group from the host community. This group is likely to include organizers, community leaders, sponsors, local businesses, and participants. The measures provided by the quantitative research, which can only describe feelings, behavior, and actions, are therefore enhanced by explanation and deeper understanding. This may lead to additional research and/or the refinement of the findings. Resident panels provide a barometer of attitudes, feelings, and behavior and can be a useful 
addition to any longitudinal research into the longer term effects of an event program. The creation of Webbased communities can provide a risk free and focused discussion of issues relating to the events with participants and comments easily monitored, recorded, and analyzed by the researcher.

The use of a range of quantitative and qualitative techniques to build up a full picture of the impacts of events is a cornerstone within the evaluation framework. Impacts cannot be evaluated with one or two simple methods or measures but need to encompass a range of complementary techniques that individually are simple to administer but when brought together form a comprehensive and meaningful evaluation of these complex phenomena.

The techniques developed partly use a staged approach where the analysis of one set of data is used to generate and refine others. However, a vital aspect of the impact evaluation framework is a holistic view of the impacts, which is only gained by synthesizing data from the numerous sources (Wood, 2004b). Each data set is therefore analyzed and interpreted and the interpretation considered alongside others. Through this process the understanding of the data is refined and the interpretations triangulated and synthesized. The resulting holistic analysis provides a much more robust and reliable interpretation than the analysis of any single aspect of the process.

Although the concepts and techniques developed through the research are aimed at encouraging the objective and unbiased evaluation of event impacts, political agendas can and will drive the focus of these measurements and influence the interpretation and use of the findings. This can already be seen in the application of the techniques by a number of agencies (contract research) where the outcome was "known" to some degree before the data were gathered and in the selection of which findings to make public or emphasize. Indeed, in his discussion of evaluation research, within the text "Real World Research,” Robson (2002) stresses the inevitable "politics of evaluation" and the greater need, therefore, for "meticulous attention to the design and conduct of the study, and to ensuring the legitimate concerns of gatekeepers have been taken into account” (p. 212). These criteria can be incorporated through the identification of "agendas" prior to the research being undertaken and through maintaining an open dialogue with interested parties before, during and after the research.
Despite the drawbacks of client-funded research these projects have provided valuable data and through recognition and reflection on their limitations and potential biases they are a valuable addition to the whole body of event impact research. In order for this to happen, the researcher needs to be able to have access to and permission to use the resulting data more comprehensively than is required by the client or indeed to collect additional data alongside the client-driven requirements. This then creates the opportunity to undertake further analysis, comparisons, and criticism, which may not necessarily be in the client's interests. However, the process is facilitated by the more open nature of the public sector and the need for transparency in local government. The management culture, therefore, tends to be less secretive and more open to sharing of information and good (or bad) practice than in the private sector. Indeed, kudos is to be gained through demonstrating publicly that objective evaluation of services is being undertaken and academic-led research can provide the gravitas needed for this.

As much of the contract research undertaken has required the participation of the client in the evaluation of services provided (the events), the research methodology could be described as participatory research. This type of research adds promotion and change to the traditional research purposes of description, understanding, and explanation (Robson, 2002) with a view to promoting organizational change and development through collaboration of researcher and researched (Argyris, Putnam, \& MacLain-Smith, 1985; Wilkinson, 1996). Festival evaluation research often involves practitioners and is undertaken with a view to improving their understanding of event impacts and their application and use of evaluation of those impacts. Through the application of these measures improvements can be made and the techniques refined.

The issues discussed above summarize the methodological issues encountered in public sector festival evaluation. Understanding can only be gained through using a variety of research methods and recognizing the importance and value of collecting diverse data in order to study the complex social issues involved. Research in the "real" social world needs to be flexible and inventive and, in order to have any validity, needs to be triangulated and supported through techniques that are at times composite, iterative, or longitudinal in nature. This, of course, suggests a complexity and resource intensity that may not sit particularly well with 
public sector practitioners. The challenge has therefore been to make these techniques accessible to those who can benefit from their use while maintaining their integrity and usefulness.

\section{A Strategic Framework for Local Government Community Festival Evaluation}

Although much of the research in event impact analysis began with studying the economic impacts (and for larger scale events the focus is still on the economic) using methods developed in tourism economics, there has been a gradual change in emphasis in the new millennium.

Research into quantifying the social impacts of events has undoubtedly increased over the last 5 years with papers on scale development by myself and Fredline, Jago, and Deery appearing at the 2001 Event Management Conference in Sydney and building on the earlier seminal work of Delamere (1997). Other researchers have also taken up the challenge and this was highlighted further by the 2005 "Beyond Economic Impacts” conference hosted by Napier University and the more recent paper trialing further measures of sociocultural impact by Small et al. (2005). However, there is still much to do in firstly convincing organizers and funders that social impacts are as important (and for some events more important) than economic measures and secondly in developing robust, flexible, and practical methods for measuring such impacts. My argument is not for a standardized set of questionnaires but for a standardized framework for developing, administering, and using impact evaluation. This framework will help researchers and practitioners to better envisage the potential impacts of local government community festivals from all stakeholder perspectives and illustrate the most appropriate ways for evaluating such impacts and then using the evaluation to inform future decisions. The framework will also move forward the economic/social impact debate providing a platform from which all potential impacts can be better understood.

Although, as stated earlier, much research already exists in the field of economic impact measurement, many of the original tools used within this have been criticized over the years and have been adapted, not always successfully, from wider measures of tourism impacts (Carlsen, 2004; Jones, 2001; Tassipoulos, 2000). For example, the use of multipliers greatly affects the outcome of any economic impact assessment and yet there is little standardization or agreement on which multipliers, if any, to use (Crompton, Lee, \& Schuster, 2001; Crompton \& McKay, 1994; Dwyer, Mellor, Mistilis, \& Mules, 2000; Matheson, 2004). Similarly, the source of information used to gain economic impact data requires careful consideration. If focusing on the recipients of expenditure, a different picture often emerges when compared with those directly spending or investing. A method of comparing both these viewpoints is therefore likely to produce more comprehensive and realistic results. The economic impact of local authority community festivals can be measured by gathering data directly from those attending, participating, or investing in the festival as well as from those in the wider community (nonattendees) whose spending patterns may have been affected by the festival. This can then be combined with information gathered from local businesses, trade associations, and local government departments to gain a further perspective. In studying the existing literature on economic impact assessment it has been possible to develop a range of research instruments that are suitable for use at local authority festivals and to trial these through a number of impact studies (Wood, 2004a; Wood, Robinson, Thomas, \& Bowdin, 2005; Wood \& Thomas, 2003). The results are favorable in that the findings appear to be as accurate as possible within the constraints and that the methods are reliable and valid. Alongside this development of economic assessment methods work done in Australia shows similar developmental processes resulting in "off-the-shelf" economic impact measurement kits. For example, the DIY Kit produced by Arts Australia (Jackson, Houghton, Russell, \& Triandos, 2005) and the software developed by Sustainable Tourism CRC in Victoria (Jago, 2004). However, from my own experience, although such kits have the benefits of comparability if widely adopted, they lose the flexibility needed to create a suitable measurement tool that meets the needs of widely differing events.

One of the earlier studies by Dwyer et al. (2000) puts forward a framework for assessing the tangible and intangible impacts of events and conventions. However, the focus of this framework is overwhelmingly economic although it provides a useful breakdown of the types of costs and benefits that are often associated with events and is one of the first major recognitions of "civic pride" as a potential social impact of events (although this term has been used in social 
capital literature for some time associated with the arts and health promotion). Later work has used this concept to develop methods for measuring the changes in social phenomena related to the hosting of festivals (Wood, 2006b) and has led to their inclusion within the evaluation framework.

Through a review of previous studies it is clear that there is a body of evidence proving the value of evaluation against wider objectives (longer term and social) rather than simply the evaluation of the festival itself (e.g., attendee enjoyment, tickets sold). Building on this, the evaluation framework presented here involves identifying potential impacts in terms of benefits and nonbenefits and recognizing that these depend on the viewpoint of the impacted stakeholder (e.g., attendee, local residents, region, and nation). Suitable methods are available for measuring each of these impacts, which can be easily applied and replicated for comparison over time and between organizers. The adoption of such a framework will undoubtedly lead to the development of sustainable events that bring a range of benefits to a variety of stakeholders and the better allocation of public funds to such events.

\section{Evaluation Theory and the Framework}

The evaluation framework combines goal-attainment, effects, stakeholder, and program theory models of evaluation and moves away from the economic cost-benefit models (Hansen, 2005). In order that stakeholder needs be addressed, both goals and impacts (effects) need to be evaluated and this needs to be done from the perspective of different stakeholder groups and within the particular context of each event. A standardized evaluation system is not therefore feasible, but a framework for developing an appropriate system for each event is.

The power and politics of local government involvement in events also suggests the need to move away from economic models, which, although legitimate if undertaken with integrity, are too often and too easily misused for political motives (Crompton, 2006). Ensuring views from all stakeholder groups are incorporated into the evaluation process and using a variety of methods and practices can help overcome/counteract the tendency for the selective gathering and publication of evaluation results. The evaluation framework suggested, therefore, entails the measurement of more than outcomes but also considers the process and the context. Multiple methods and a broad range of information-gathering processes are needed to cover the complexity of festival impacts. These should combine, whenever possible, both positivist and interpretivist perspectives with the proviso that these will produce a greater understanding of festival impacts but not absolute proof of causal relationships.

A review of evaluation theory and in particular public sector evaluation theory has led to recognition of the importance of the context of the festival and the need for community/organizer participation in the evaluation process. The purpose of evaluation within the public sector can be categorized as being for accountability, for learning, for program management and development, or as an ethical obligation (McDonald, Rogers, \& Kefford, 2003). These are certainly valued reasons for undertaking festival evaluation, and the framework attempts to incorporate these aims within it. This helps to ensure that, in practice, there is learning and development rather than mere measurement and accountability of fund use. Also of interest is the idea of "who evaluates." Should the evaluation be independent and external or integrated within program delivery involving practitioners? Working collaboratively along with community and organizer participation can capitalize on the strengths (Green \& South, 2006; Katz \& Peberdy, 1997) by providing both "outside" objectivity and "inside" contextual and practitioner know-how. This collaboration and participation is necessary also in order to build evaluation capability in public sector and community organizations (McDonald et al., 2003). Indeed, McDonald et al. suggest that only evaluation design and implementation can be done by external parties and that the other evaluation processes of describing, framing, using, and overall management of the evaluation framework must be done internally.

In the public sector literature performance measurement has been identified as being different from the private sector while using some of the same basic premises. Bolton (2003), in a study of US public sector performance measurement, suggests that measures should:

- be significant in that they focus on key success factors;

- include different perspectives reflecting all key stakeholders' views; 
- be used together rather than in isolation;

- be balanced between quantitative and qualitative;

- be discriminating in ability to recognize significant findings;

- be unobtrusive in not disrupting primary tasks.

Similarly, the "best value" concept used in UK local government performance measurement demands in-depth analysis and comparison, diagnostic activity to identify areas for potential improvement, and the development of improvement plans (Liddle, 1999). These aspects of public sector analysis have been particularly important in developing the process that is central to the evaluation framework (Fig. 2).

Although much of the language used in discussing public sector performance measurement and operations is taken from private sector research and theoretical concepts, the two sectors remain fundamentally different. The relationship between citizen and government is not an exchange. Public services are not exchanged for the payment of taxes, the relationship has been described as one of "mutual commitment" (Walsh, 1994). Therefore, although the methods and concepts proposed in the framework have developed out of fields such as marketing research, they have been adapted in order to reflect the differences between consumer and citizen. This differing viewpoint helps to identify the wider aspects of event impact assessment and moves the focus away from simply measuring the satisfaction of the attendees on the day. The potential benefits and costs to all impacted citizens need to be evaluated and the agendas of those involved recognized.

The framework provides a way of taking forward the research into festival evaluations within the context of the wider evaluation literature and taking into account the relative immaturity of evaluation practice and research in the field of community festivals. Evaluation frameworks impose a structure on hard to define constructs and can provide clarity by identifying core domains of measurement and thereby focusing data collection developed from empirical research and consultation with stakeholders. This helps to give face validity and credibility to the methods and processes suggested (Green \& South, 2006). Frameworks (as opposed to process models) can be more flexible and applied to different festivals in different settings, coping with the diversity of domains and actors that arise in festival and event studies.

\section{Aspects of the Framework}

Levels and Types of Impact. The social and economic impacts of local authority community festivals are partly determined (in magnitude and valence) by the perspective of the affected stakeholders. It is therefore important to recognize that, for example, at a national level there may be positive economic benefits whereas at a local level these may be minimal or negative. A larger scale event (such as European Capital of Culture) will have both local and national social benefits but these will differ in type and strength (Richards \& Wilson, 2004). The importance of the stakeholder's perspective is clear and in some respects this negates the potential for generic measurement tools. The tools themselves cannot, therefore, be standardized as they would not be appropriate for all levels of impact. The levels identified for community-based events and festivals can be categorized as societal, regional, community, and personal (Wood et al., 2006).

Within each level it is possible to categorize a number of types of impact, both positive and negative. These have been identified through secondary research and through previous field research and consultancy undertaken. However, what has become clear is that an exhaustive list is unlikely to be accurate or indeed helpful. The important factor is to identify those impacts that are of interest for each particular festival or study. This may, as discussed earlier, depend upon the stakeholders involved and/or may be determined by the objectives of the festival. Here, however, it could be argued that there is "a chicken and egg" situation. Recognizing likely impacts before the event in order to set objectives may not be possible as many impacts may not be foreseen and can only be identified after the event. This is where an accessible shared body of knowledge would provide support, allowing festival organizers, funders, and supporters to learn from the experiences and evaluations of others and be able to use these to develop appropriate objectives.

Although it is likely that economic impacts will be of importance to several stakeholders, much of the previous empirical research and consultancy projects indicate that this type of impact is minimal and is often only directly relevant to those involved in the event itself, such as the venue, the stallholders, participants, performers, and sponsors. These groups will benefit financially but are often not from the local community or even the region, therefore limiting any direct economic 


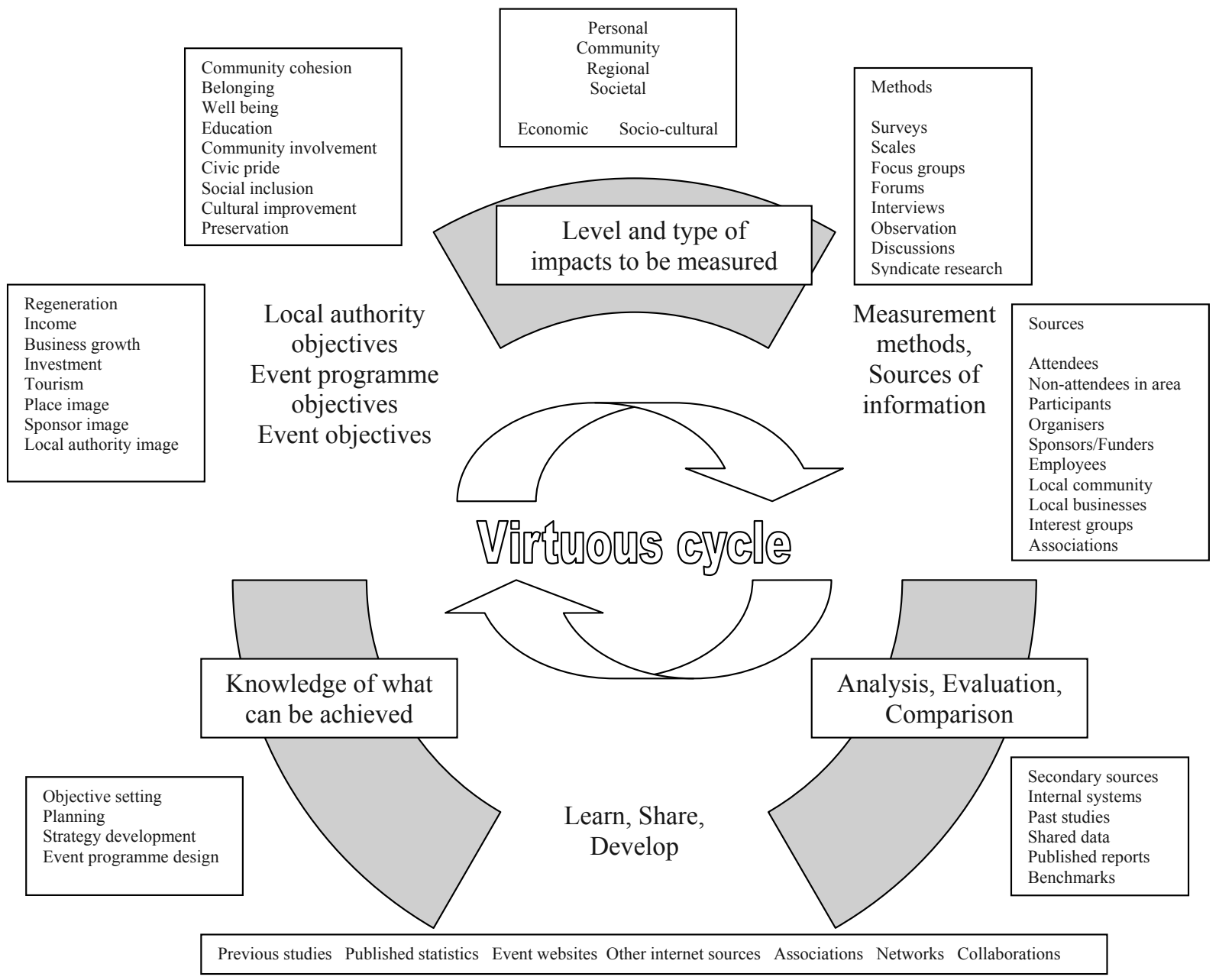

Figure 2. A framework for community festival evaluation.

benefit. The community, the local businesses, and individuals tend not to be subject to, or perhaps, recognize, a positive (or negative) economic impact but are more strongly affected by the intangible social impacts. However, it also needs to be recognized that some of the potential social impacts of community festivals will have a "knock on" economic effect, although proven links between these are outside the realm of this research. For example, it is accepted in several local authority performance measures that increased pride in the area leads to higher economic activity and that social cohesion leads to lower levels of certain types of crime.

Types of Measurement. Each impact identified needs to be evaluated and this evaluation needs to be achievable within the constraints of time, money, and expertise while still providing meaningful and robust data.

What evolves is a range of techniques that have now been tried and tested and appears to meet the needs of local government community festival organizers. Due to the variety of potential impacts, a specific tool has not been developed for each but the groundwork has been done to allow others to adapt and develop tailored methods. For example, the development of the civic pride scale (Wood, 2006b) shows how a scale could be developed to measure other social constructs and then be applied before and after the event. Economic data gathered using simple visitor/participant spend alongside local business turnover information pro- 
vides a reliable and consistent method for estimating the economic effects of an event. These instruments also allow for switching costs and include surveys of nonattendees. The quantitative and qualitative primary research methods developed for event evaluation only form part of the overall evaluation. The importance of secondary data should not be overlooked, and those with an interest in evaluating events need to build market intelligence gathering and other secondary sources of information into the evaluation. This helps to give the wider focus (external rather than internal) that has been shown to be successful. Indeed, many researchers in the field of marketing information systems (Talvinen, 1995; Wright \& Ashill, 1998; Xu \& Kaye, 1995) suggest that the majority (up to 80\%) of information used by an organization for decision making should be gained from outside their normal operating environment and that much of this will be gleaned from published data. Asking attendees is, therefore, only a small part of the overall picture and needs to be supplemented through widening the sources of primary data (nonattendees, wider community, businesses, pressure groups) and through continual monitoring of secondary sources (published evaluations, tourism statistics, trends data, competitor websites), much of which is free and accessible via the Internet and via other shared resources.

Information Management. The levels and types of impact and the variety of information sources needed to evaluate these suggest a complexity that must be managed within an appropriate information system. This system requires some informality and flexibility and should make use of networks, collaborations, trade associations, and syndicated research. Within local government much information can be gained through other existing information systems and through internal as well as external systems. The less competitive nature of public services allows for greater sharing of information within and between local authorities (McIvor, McHugh, \& Cadden, 2002) and this can be leveraged to great effect for better understanding event impacts. Similarly, information and research resources can be shared with sponsoring, organizing, and participating bodies.

The challenge in the end is not the gathering of event impact information but managing this information so that it can be learned from and used effectively for decision making and long-term strategy development.
Information overload can prevent this from happening and needs to be overcome through practical information management. Recognition that what is known at any one time is less important than the ability to learn can help focus on information use rather than information storing. Much information has a short shelf life and, although trends and historical data are important, the detail in past data can be discarded in favor of more up-to-date information. This applies equally to academic researchers, as in order to develop a deeper understanding of event impacts it is vital to gather current data at a variety of events and to analyze these within the context of existing knowledge.

Information Use. The practical application of this framework will start to develop a growing body of knowledge that ideally should be accessible by both academic researchers and event practitioners and indeed any other stakeholders of the festivals.

From a practitioner point of view, impact information along with wider market intelligence can be used to develop event programs that meet the short- and long-term objectives of the local authority. These may be in terms of economic regeneration, income, community cohesion, civic pride, education, well-being, or indeed promotion of the authority itself. The important aspect is to move away from a mere evaluation of the event itself in terms of audience enjoyment, health and safety, attendee numbers, etc., to measurement of what the event can achieve for those involved and the wider community. As previous researchers (McAdam \& Reid, 2000) have found that knowledge management is more developed as a management philosophy in the public sector, the door is open for better and more effective use of event impact evaluation data.

Sponsors can use such information to determine their future business plans in terms of which events meet their communication goals and participants equally can use impact evaluation data to decide on the types of event that are of the most benefit.

Therefore, making such information publicly available allows it to become a data source for others and encourages learning and increasing sophistication in local authority event programming and also aids the development of benchmarks and other means of comparison. Several recent studies have called for greater understanding of the potential of arts and cultural festivals as part of urban planning, tourism development, and community betterment and for more holistic as- 
sessment (Quinn, 2005; Sherwood et al., 2005). Their limitations as well as their potential, if better understood, will undoubtedly lead to more strategic and effective allocation of public funds.

Process. The final component of the framework is the development of a process for evaluating the impacts of local authority community-based festivals. This process is iterative in nature to highlight the learning cycle implicit within impact evaluation. The process incorporates the reporting and operating constraints and requirements found within local government. These include measuring against mission and objectives, comparison of actual with target performance, developing benchmarking partners and triangulating using complementary measures, focusing on what stakeholders think and feel (Bolton, 2003).

The process model, although developing out of the rational model of policy evaluation, addresses some of the criticisms of this (Hambleton \& Thomas, 1995) through the inclusion of a wider variety of viewpoints, recognition of the politics of evaluation, and by not limiting the evaluation to "known" or stated objectives.

The stages in the process can be summarized as:

- identify the relevant levels of impact;

- identify the potential impacts within each level;

- select impacts to measured related to stakeholder objectives;

- select measurement methods for each impact (within resources and primary and secondary sources);

- apply the measures;

- identify any unforeseen impacts;

- analyze, evaluate, and compare findings;

- use findings to learn, share, and develop.

This process allows for the development of a virtuous cycle of improvement and learning based on thorough impact evaluation combined with wider sources of information. Creating a better knowledge of what can be achieved through community festivals and events will enable theorists and practitioners to develop the field further. Event organizers and local authority strategic planners will be better able to determines objectives for their event programs, taking advantage of their potential and being aware of their limitations. Academics will be able to further study these impacts in order to identify the longer term benefits and costs along with more sophisticated ways for measuring and assessing these.

The aspects of the framework discussed above are summarized in Figure 2.

\section{Conclusion}

The framework is used to produce a map of the complex and interrelated aspects inherent within festival evaluation. Its focus is on community festivals with some local government involvement. It, therefore, has not been designed to meet the specific needs of other types of event (mega-events, private sector events, larger sporting events, and trade and industry events). Although many of the same premises will hold true for these other events, the same drive to evaluate may not.

The framework is intended to incorporate a wider view of evaluation than has been used so far in event evaluation. It suggests that the views of all stakeholders are considered, that evaluation takes place within specific and unique contexts (and therefore cannot be standardized), a wide range of methods and sources of information is required to give a full and balanced view, that outcomes or objectives although important are not the only aspects to evaluated, and that a costbenefit analysis or economic evaluation is not suitable for this type of festival where many of the effects are intangible, social, and long term.

The next challenge in the development of the framework is to empirically demonstrate its applicability to a wider range of festivals and events and to develop methods for evaluating more of the social impacts of festivals to provide further specific tools for inclusion in the framework.

By applying and critiquing this framework both practitioners and academics will add to the existing body of knowledge and move forward the study and application of event impact evaluation.

\section{References}

Argyris, C., Putnam, R., \& MacLain-Smith, D. (1985). Action science. San Francisco: Jossey-Bass.

Beattie, A. (1995). Evaluation in community development for health: An opportunity for dialogue. Health Education Journal, 54, 465-472.

Blaug, R., Horner, L., Kenyon, A., \& Lekhi, R. (2006). Public value and local communities. London: The Work Founda- 
tion.

Bolton, M. (2003). Public sector performance measurement: Delivering greater accountability. Work Study, 52(1), 20-24.

Boyett, I. (1996). The public sector entrepreneur-a definition. International Journal of Public Sector Management, 9(2), 36-51.

Carlsen, J. (2004). The economics and evaluation of festivals and events. In I. Yeoman, M. Robertson, J. Ali-Knight, U. McMahon-Beattie, \& S. Drummond (Eds.), Festival and events management: An international arts and cultural perspective (pp. 246-259). Oxford: Butterworth Heinemann.

Carlsen, J., Getz, D., \& Soutar, G. (2001). Event evaluation research. Event Management, 6, 247-257.

Cousins, L. (1990). Marketing planning in the public and non-profit sectors. European Journal of Marketing, 24(7), 15-30.

Crompton, J. L. (2006). Economic impact studies: Instruments for political shenanigans? Journal of Travel Research, 45, 67-82.

Crompton, J. L., Lee, S., \& Schuster, T. J. (2001). A guide for undertaking economic impact studies: The Springfest example. Journal of Travel Research, 40, 79-87.

Crompton, J., \& McKay, S. (1994). Measuring the economic impact of festivals and events. Some myths, misapplications and ethical dilemmas. Festival Management \& Event Tourism, 2(1, 33-43.

Delamere, T. A. (1997). Development of a scale to measure the social impact of community festivals. Journal of Allied Recreation Research, 22(4), 293-315.

Derrett, R. (2002). Making sense of how festivals demonstrate a community's sense of place. Paper presented at Events and Place Making: Building Destinations and Communities Through Events Conference, UTS, Sydney, July.

Dwyer, L., Mellor, R., Mistilis, N., \& Mules, T. (2000). A framework for assessing "tangible" and "intangible" impacts of events and conventions. Event Management, 6, 175-189.

Falassi, A. (Ed.). (1987). Time out of time: Essays on the festival. Albuquerque: University of New Mexico Press.

Fredline, L., Jago, L., \& Deery, M. (2003). The development of a generic scale to measure the social impacts of events. Event Management, 8, 23-37.

Getz, D. (2000). Developing a research agenda for the event management field. In J. Allen, R. Harris, L. Jago, \& A. Veal (Eds.), Events beyond 2000: Setting the agenda. Sydney: ACEM, UTS.

Getz, D. (2002). Events studies and event management: On becoming an academic discipline. Journal of Hospitality and Tourism Management, 9(1), 12-23.

Getz, D. (2005). Event management \& event tourism (2nd ed.). New York: Cognizant Communication.

Goldblatt, J., \& Nelson, K. (Eds.). (2001) The international dictionary of events management (2nd ed.). New York: John Wiley and Sons.

Green, J., \& South, J. (2006). Evaluation. Maidenhead: Oxford University Press.

Hackney, R. A., \& McBride, N. K. (2004). The efficacy of information systems in the public sector: Issues of context and culture (Working paper). Manchester Metropolitan University and De Montfort University.
Hadi, Z. A., \& McBride, N. (2000). The commercialisation of public sector information within UK government departments. International Journal of Public Sector Management, 13(7), 552-570.

Hall, D., \& Richards, G. (Eds.). (2003). Tourism and sustainable community development. London: Routledge.

Hambleton, R., \& Thomas, H. (Eds.). (1995). Urban policy evaluation: Challenge and change. London: Paul Chapman Publishing.

Hansen, H. F. (2005). Choosing evaluation models: A discussion on evaluation design. Evaluation, 11(4), 447-462.

Harris, R., Jago, L., Allen, J., \& Huyskens, M. (2001). Towards an Australian event management research agenda: First steps. Event Management, 6, 213-221.

Jackson, J., Houghton, M., Russell, R., \& Triandos, P. (2005). Innovations in measuring economic impacts of regional festivals: A do-it-yourself kit. Journal of Travel Research, 43(4), 360-367.

Jago, L. (2004). Standardised software for economic impact assessment of local government events. IFEA Annual Conference Boston, MA, November.

Janiskee, R. (1980). South Carolina's harvest festivals: Rural delights for day tripping urbanites. Journal of Cultural Geography, 1, 96-104.

Jones, C. (2001). Mega-events and host-region impacts. Determining the true worth of the 1999 Rugby World Cup. International Journal of Tourism Research, 3, 241-251.

Katz, J., \& Peberdy, A. (1997). Promoting health knowledge and practice. Basingstoke: Macmillan.

Liddle, D. (1999). Best value-the impact on libraries: Practical steps in demonstrating best value. Library Management, 20(4), 206-212.

Long, P., \& Robinson, M. (2004). Festivals and tourism: Marketing, management and evaluation. Sunderland: Business Education Publishers.

Marcouiller, D. (1995, April). The community impacts of festivals and events. Community Economics Newsletter, 222.

Matheson, V. A. (2004). Economic multipliers and mega-event analysis (Working paper 04-02). College of the Holy Cross, Department of Economics.

McAdam, R., \& Reid, R. (2000). A comparison of public and private sector perceptions and use of knowledge management. Journal of European Industrial Training, 24(6), 317-329.

McDonald, B., Rogers, P., \& Kefford, B. (2003). Teaching people to fish? Building the evaluation capability of public sector organizations. Evaluation, 9(1), 9-29.

McIvor, R., McHugh, M., \& Cadden, C. (2002). Internet technologies: Supporting transparency in the public sector. The International Journal of Public Sector Management, 15(3), 170-187.

Pugh, C., \& Wood, E. H. (2004). The strategic use of events within local government: A study of London Borough Councils. Event Management, 9(1), 61-71.

Quinn, B. (2005). Arts festivals and the city. Urban Studies, 42(5/6), 927-943.

Richards, G., \& Wilson, J. (2004). The impact of cultural events on city image: Rotterdam, Cultural Capital of Europe 2001. Urban Studies, 41(10), 1931-1951.

Robson, C. (2002). Real world research (2nd ed.). Oxford: 
Blackwell Publishing.

Sherwood, P., Jago, L., \& Deery, M. (2005). Triple bottom line evaluation of special events: Does the rhetoric reflect reporting? 3rd International Event Management Conference, ACEM University of Sydney.

Small, K., Edwards, D., \& Sheridan, L. (2005). A flexible framework for evaluating the socio-cultural impacts of a (small) festival. International Journal of Event Management Research, 1(1), 66-77.

Smith, G., \& Saker, J. (1992). Developing marketing strategy in the not-for-profit sector. Library Management, 13(4), 6-20.

Springett, J. (2001). Appropriate approaches to the evaluation of health promotion. Critical Public Health, 11(2), 139-151.

Stone, W. (2001). Measuring social capital. Towards a theoretically informed measurement framework for researching social capital in family and community life (Research paper No. 24). Australian Institute of Family Studies.

Talvinen, J. M. (1995). Information systems in marketing. Identifying opportunities for new applications. European Journal of Marketing, 29(1), 8-25.

Tassipoulos, A. (2000). Event management. Lansdowne: Jute Education (Pty) Ltd.

Thomas, R., \& Wood, E. H. (2003). Event based tourism: A survey of local authority strategies in the UK. Local Governance, 29(2), 127-136.

Vaughan, D. R., Farr, H., \& Slee, R. W. (2000). Estimating and interpreting the local economic benefits of visitor spending: An explanation. Leisure Studies, 19, 95-118.

Walsh, K. (1994). Marketing and public sector management. European Journal of Marketing, 28(3), 63-71.

Wilkinson, M. B. (1996). Action research for people and organisational change. Brisbane: Queensland University of Technology.

Wood, E. H. (2002a). An analysis of the predictors of business performance in small tourism and hospitality firms. International Journal of Entrepreneurship and Innovation, 3(3), 201-210.

Wood, E. H. (2002b). Events, civic pride and attitude change in a post-industrial town. In Events and place making (pp. 788-851). Sydney: UTS.

Wood, E. H. (2004a). Measuring the social and economic impacts of local authority events. International Journal of Public Sector Management, 18(1), $37-53$.
Wood, E. H. (2004b). Marketing information for impact analysis and evaluation. In I. Yeoman, M. Robertson, J. Ali-Knight, U. McMahon-Beattie, \& S. Drummond (Eds.), Festival and events management: An international arts and cultural perspective. Oxford: Butterworth Heinemann.

Wood, E. H. (2006a). The internal predictors of business performance in small firms: A logistic regression analysis. International Journal of Small Business and Enterprise Development, 13(3), 441-453.

Wood, E. H. (2006b). Measuring the social impacts of local authority events: A scale to quantify civic pride. International Journal of Non-Profit and Voluntary Sector Marketing, 11, 165-179.

Wood, E. H., \& Robinson L. S., \& Thomas, R. (2006). Evaluating the social impacts of community and local government events: A practical overview of research methods and measurement tools. In S. Fleming \& F. Jordan (Eds.), Events and festivals: Education, impacts and experiences (pp. 81-92). Eastbourne: Leisure Studies Association.

Wood, E. H., Robinson, L., Thomas, R., \& Bowdin, G. A. (2005). The contribution of community festivals to tourism: An assessment of the impacts of rural events in Wales. Paper presented at Assessing the Impact of Tourist Events Université Nice, TMP Research Group, Juan Les Pins, France, December 8-9.

Wood, E. H., \& Thomas, R. (2003). Evaluation of the social and economic impacts of Preston Mela. Engaging Our Communities, Leeds Metropolitan University Research Conference, September.

Wood, E. H., \& Thomas R. (2006). Measuring cultural values: The case of residents' attitudes at the Saltaire Festival. Journal of Tourism Economics, 12(1), 137-145.

Worrall, L., Collinge, C., \& Bill, T. (1998). Managing strategy in local government. International Journal of Public Sector Management, 11(6), 472-493.

Wright, M., \& Ashill, N. (1998). A contingency model of marketing information. European Journal of Marketing, 32(1/2), 125-144.

$\mathrm{Xu}, \mathrm{X} ., \mathrm{\&}$ Kaye, R. G. (1995). Building market intelligence systems for environment scanning. Logistics Information Management, 8(2), 22-29.

Yanow, D. (2000). Conducting interpretive policy analysis (Qualitative Research Methods Series, 47). London: Sage Publications. 